\title{
4 Semantic range of instruments, agents \& forces
}

In this chapter I will propose solutions to some of the instrument-related problems raised in the previous chapter, such as ISA and the restrictions that it occurs with.

The most pressing question is what an instrument really is. It has been argued that instruments are a subtype of the more basic effector in RRG: Instruments are intermediary effectors (x-argument of do' $(\mathrm{x}, \varnothing)$ ) in a causal chain. Instruments that are not causally embedded are implements. In chapter 5, I will formally introduce an alternative way to distinguish instruments from implements. Until then, all examples will feature instruments unless indicated otherwise. It is important to realize that instruments (and implements) are components of the logical structures. Most (English) examples in this dissertation use the with-PP format, which is the most common linking strategy for instruments and implements. Consider:

(1) a. Seymour sliced the salami with a knife. (Lakoff 1968: 6-7)

b. Adewale opened the locked box with a key.

Other linking strategies will be explored in chapter 8. The full LSs for the sentences in $(1 \mathrm{a}-1 \mathrm{~b})$ are given in $(2 \mathrm{a}-2 \mathrm{~b})$. As I pointed out in chapter 3 , in the 'usual' logical structures employed in RRG, the use' predicate $^{1}$ is often left out because it is clearly implied by the rest of the structure. The same is true for the embedded predicate functioning as the second argument of intermediate $\mathbf{d o}^{\prime}$. Leaving them out is a matter of clarity. The 'full' LSs corresponding to (1) are given in (2).

1 The intermediate cut' predicate is also usually left out, for the very same reasons. For the sake of clarity, I prefer to use the reduced LSs in this dissertation. 
(2)
a. [do' (Seymour, [use' (Seymour, knife)])] CAUSE [[do' (knife, [cut' (knife, salami)])] CAUSE [BECOME cut' (salami)]]
b. [do' (Adewalé, [use' (Adewalé, knife)])] CAUSE [[do' (key, [open' (key, door)])] CAUSE [BECOME open' (door)]]

This full representation is rarely used and this is true for this dissertation as well. The 'simple' version of ( $2 b)$ is given below in (3).

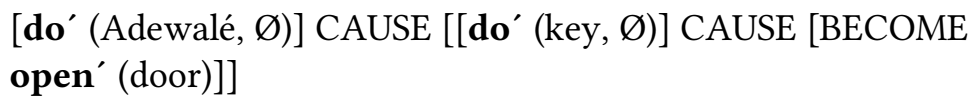

This chapter focuses on how the semantic space of instruments can be characterized. I will also go into concepts that are seemingly related to instruments, such as implements and forces including the less canonical ones. Consider:
a. Fohn destroyed the barn with the crane.
b. The crane destroyed the barn with a load of cinder blocks.
c. The storm destroyed the levee with huge tidal waves.

The cases above are challenging for standard explanations of instruments for various reasons. For example, in (4a) and (4b) the same inanimate referent occurs as an instrument and as a participant taking an instrument, and in (4c) the force argument takes an instrument itself. To capture the distinctions between such referents, I will argue in favor of a revised and expanded animacy hierarchy.

\subsection{Degrees of animacy \& autonomy}

In the following sections, I will explore the semantic space that agents, forces and instruments occupy, together with several problematic borderline cases. How can that semantic space be characterized? The Van Valin-Wilkins hierarchy (1996) was intended to capture if and when effectors are read as agents. Animacy is a central component of this hierarchy. Animacy also features prominently in Grimm's (2005, 2013) 
approach. As a part of mapping semantic space I will explore the role of animacy further and argue in favor of an additional, interrelated concept called autonomy.

\subsubsection{Animacy}

Animacy is a category that often stays in the background and is taken for granted, despite its pervasive role in grammar and despite substantial evidence in favor of including it as a central component in a theory of language (Dahl \& Fraurud 1996: 47). Animacy manifests itself in language mainly in two ways: 1) It influences grammatical rules (case assignment and word order, for example) and the choice of expression (Aissen 2003) and 2) statistical regularities can be observed (Dahl 2008: 141). Yamamoto (1999: 41-70) provides evidence for the cross-linguistic influence of animacy on case marking, word order, subject selection and topicality. Consider the following examples from Malayalam:
a. Avan kutti-ye aticcu.
3SG.M child-ACC beat.PST
'He beat the child.' (Fauconnier 2011: 533-534)
b. Avan oru pafu-vine vanni.
3SG.M INDEF cow-ACC buy.PST
'He bought a cow.' (de Swart et al. 2008: 132)
c. Avan pustakam vaayiccu.
3SG.M book read.PST
'He read the book.' (Fauconnier 2011: 533-534)

In Malayalam, the direct object receives accusative case only if the referent is animate. Fauconnier (2011: 533, 541-542) theorizes that unexpectedness plays a crucial role in such an assignment: Statistically, most direct objects are inanimates ${ }^{2}$ (89\% in Swedish for example; Dahl

$2 \quad$ Grewe et al. (2006) provide psycholinguistic evidence for the importance of animacy. They manipulated the animacy of certain referents, thereby violating the principle that animates come before inanimates ('animates first'). They found that such violations activate the same brain areas that are activated when syntactic principles are violated. There is also evidence of knowledge pertaining to animates being sep- 
2008: 142). One strategy to deal with this 'unexpected object' is to assign a different case marker to it (or in the case of Malayalam, a marker). In the same vein (and following Silverstein 1976), Fauconnier (2011: 541ff.) theorizes that languages generally prefer to avoid inanimate subjects, or, if they are allowed, they are treated differently from animate subjects. Japanese (Kuno 1973: 31), for example, strongly disprefers inanimate subjects, instead requiring (at least) higher animals as subjects.
a. "Taihuu ga mado o kawasita. Typhoon SUBJ window OBJ break.PST
'The typhoon broke the window.' (Kuno 1973: 31)
b. Sono otoko ga mado o kawasita.
DEF man SUBJ window OBJ break.PST
'The man broke the window.' (own data)

The Australian language Jingulu assigns instrumental marking to inanimate subjects, whereas animate subjects receive ergative marking (Pensalfini 2003: 178, 189):
a. Babi-rni
ikiya-rnarnu-nu ibilkini.
Older brother-ERG wet-3SG>1SG-PST water
'My brother wet me.'
b. Darrangku-warndi maya-ngarnu-nu.
Tree-INS
hit-3SG>1SG-PST
'A tree hit me.'

But also in languages with less extensive morphology like English or Dutch, animacy can have a profound influence on grammatical rules: Rosenbach (2008) theorizes that the animacy of the referents in possessive constructions influences whether an s-genitive or an of-genitive is selected in English. Similarly, Bresnan \& Hay (2008: 250) argue that English dative shift is partly dependent ${ }^{3}$ on animacy: Animate recipient

arately stored from knowledge related to inanimates in the brain (cf. Rosenbach 2008: 157).

3 Bresnan \& Hay (2008: 246) provide evidence that this animacy effect is also dependent on the variety of English. New Zealand English is more sensitive to animacy considerations than US English. 
arguments are likely to be expressed in a double object construction whereas inanimate recipients have a preference for the prepositional dative. In Dutch, for instance, animates are more likely to be pronominalized than inanimates (Vogels et al. 2014: 116).

The examples discussed above illustrate that animacy can have a substantive influence on the grammar of many languages and should more generally - be included in theories of language (cf. Bresnan et al. 2001). In what follows, I will argue in favor of a revised animacy scale, mainly drawing from Van Valin \& Wilkins (1996), Grimm (2005, 2013), Schlesinger (1989) and Yamamoto (1999).

In the previous chapter, I pointed out that it is possible to make the logical structures explicit with a matching paraphrase, thereby revealing whether there is causal embedding or not. In some cases, the instrument is causally embedded, but ISA is nevertheless impossible. In the examples in (3.50), ISA was shown to be ungrammatical in Dutch but acceptable in English despite the instrument being causally embedded in both languages. Furthermore, some instruments allow ISA whereas others do not, even if the predicate remains the same. I will argue that animacy is directly relevant for instruments, and more specifically, for the acceptability of ISA within and across languages. Roughly speaking, I will argue that the argument positions in a given logical structure are open to a specific portion of semantic space (cf. Grimm 2005, 2013). In short, I will make a case for animacy as one of the drivers of ISA. This is in line with Yamamoto's claim (1999: 67) that more animate entities will occupy more salient positions in clauses and discourse. Zaenen et al. (2004: 118) argue that positions on the animacy hierarchy correlate with the accessibility of the referents for the morphosyntax. My approach to ISA can be seen as an extension of both these claims. In languages that allow ISA, the instrument-referent's properties relative to the predicate's requirements will determine whether ISA can take place. The referent must be high enough on a revised animacy scale, relative to the requirements of the predicate. One problem, however, is that animacy is often used in a somewhat undefined way, similar to many linguists' use of thematic relations. I thus agree with Rosenbach (2008) and Grewe et 
al. (2006: 1397), amongst others, in treating animacy as an important, genuine factor in grammatical behavior, rather than an epiphenomenon.

Most animacy hierarchies in the literature are roughly based on the one proposed by Silverstein $(1976,1981)$. Silverstein's original hierarchy is a very fine-grained one. However, in the general literature on animacy, it is usually drastically simplified to a coarse three-way distinction, between humans, other animates/animals and inanimates. This distinction is motivated as a hierarchical scale (Dahl 2008: 141, Yamamoto 1999: 1, 9, Foley \& Van Valin 1985: 288). It is ultimately an assumed cognitive distinction between animates and non-animates and (by analogy) between humans and non-humans (Yamamoto 1999: 9).

(8) human > other animate $>$ inanimate

Whatever form such a hierarchy may take, I largely follow Dahl (2008), Yamamoto (1999) and Comrie (1981: 178) with respect to the general properties of animacy: 1) The borders between the different 'steps' are fuzzy and membership in the categories can be fluid (Yamamoto 1999: 9), 2) the (human) self is the model for other humans and other animates, which are in turn models for lower-ranking entities (cf. a ranking of 'sameness' to one's self), 3) personhood appears to be a core trait of prototypical animacy (anthropocentric human cognition, see below), 4) animacy is cognitively deeply rooted in humans due to it being a central component ('sameness') in the organization of social life, 5) animacy is a property of a referent (Comrie 1981: 56, 179), 6) linguistic animacy is distinct from biological animacy (being 'alive', cf. Yamamoto 1999: 1ff.) and 7) animacy is a universal category that exists independently of its language-particular realization (Comrie 1981: 179). Animacy thus refers to the cognitive and ontological status of an entity (Yamamoto 1999: 36) and the distinction is considered to be fundamental and universal to human cognition (Boas 1911: 67).

The hierarchy in (8) is quite primitive and there is an abundance of explicit (and implicit) proposals to be found in the literature to refine it. Yamamoto (1999: 2) considers this hierarchy as the core component of any animacy hierarchy; it constitutes what she calls the General Animacy Hierarchy (Yamamoto 1999: 2) or animacy per se. Yamamoto (1999: 1) 
considers the General Animacy Hierarchy as a basic cognitive scale, which interacts with several others that further refine the basic scale's echelons. The most important one in this respect is the Hierarchy of Persons, which effectively provides an ordering within the human echelon (Yamamoto 1999: 3, 6).

Van Valin \& Wilkins (1996: 316) argue that, for example, $1^{\text {st }}$ person pronouns rank higher than $2^{\text {nd }}$ or $3^{\text {rd }}$ person pronouns, because one can be sure of one's own intentions, but not of those of others. Langacker (1991: 306-307) arrives at a similar conclusion, focusing on the notion of empathy: One shows more empathy for the self than for the individual one is speaking to and even more than for a third party. Both these points of view lead the respective authors to treating $1^{\text {st }}$ persons as occupying a higher position on the hierarchy than second persons and so on. This does not mean that second persons are considered to be less animate than first persons, however. The Hierarchy of Persons simply provides a further refinement of the human section of the hierarchy, all its members being equally animate. This line of thought reveals that animacy hierarchies are both anthropocentric and egocentric (cf. Yamamoto 1999: 9f., 37). The speaker is at the center of the world and all other entities are judged and considered from that perspective (Langacker 1991: 307). Humans (and particularly the self) are seen as the 'supreme representatives of all animate beings' (Yamamoto 1999: 9) and imbue other entities (even those that are inherently inanimate) with degrees of animacy. Due to the speakers investing different degrees of animacy to different referents, certain entities will be considered more animate than others. For instance, Yamamoto (1999: 2-3) argues that cats will be considered more animate than amoebae, even though from a biological point of view both are equally alive.

Some linguists also attempt to refine the other echelons. For instance, Zaenen et al. (2004: 121) and Øvrelid (2006: 53) propose to further subdivide the 'other animates'-category by not only recognizing animals as subtypes but also organizations, intelligent machines and vehicles. Likewise, the inanimate category is enriched with concepts such as concrete inanimate, non-concrete inanimate, place and time. The reason to provide further divisions is to be able to handle the grey, 'fuzzy' area that 
exists between referents. Such borderline cases include machines, especially those that have human traits like intelligence (Yamamoto 1999: 18) or a decision-making ability that is commonly found in various types of Artificial Intelligence. Furthermore, Yamamoto points out that machines that have an internal power source are often seen as more animate than those that receive their power from an external source.

Often however, such proposed categories are not ranked respective to each other, whereas examples in chapter 3 illustrated that more complex machines are better ISA-candidates than less complex ones. This means that some form of internal ranking should be imposed on the finer categories.

I propose the animacy hierarchy in (9). In my proposal, I do not propose all or nothing parameters for animate beings. I agree with Yamamoto (1999) and others that animacy is a gradient, fluid notion. I therefore consider the superordinate labels animate and inanimate as vaguely delineated portions of the hierarchy rather than discrete categories.

(9) Non-entity < abstract entity < concrete entity (immobile) $<$ concrete entity $<$ animate entity $<$ (pseudo-)sentient entity $<$ anthropomorphic entity $<3^{\text {rd }}$ person $<2^{\text {nd }}$ person $<1^{\text {st }}$ person

Animate entity is defined the same way that [+animate] is defined in the Van Valin- Wilkins Hierarchy (1996: 314): an entity that feels, responds and moves. This does not imply sentience, however. By way of clarification, I have repeated the scale's steps below with types of referents and example referents (the three highest echelons are self-explanatory and have not been repeated). (Pseudo-)sentient entities are those that are assumed to have the ability to judge intentions in others ${ }^{4}$ and/or the ability to make independent decisions. This includes computers and other forms of Artificial Intelligence. I do not sharply delineate between these two features as I assume them to be somewhat interdependent.

Anthropomorphic refers to the prototypical nature of human beings, i.e. the entity talks, walks, has limbs, potentially even has emotions (cf.

$4 \quad$ This was inspired by Miller and Johnson-Laird (1976: 92ff., 100ff.) and Tomasello (2003). The concept of intention reading features prominently throughout Tomasello's work. 
Zaenen et al. 2004: 121). My proposed category also includes entities that are only superficially human in appearance. For instance, in Zaenen et al.'s (2004: 122) experiment, the fictitious Vulcan race was consistently ranked as human by all participants. I theorize that this extends to supernatural or fictitious entities like ghosts, vampires and wookies. Bresnan \& Hay (2008: 249) also argue in favor of grouping such beings under human. Because of this, I prefer the label anthropomorphic to human. Furthermore, animals are also often anthropomorphized and referred to as if they were human (Yamamoto 1999: 13). In this case, they would be ranked as anthropomorphic in my approach.

(10) a. Non-entity: events, properties (birth, death, tall, short)

b. Abstract entity: ideas, notions (federalism, revolution)

c. Concrete entity (immobile): places, landmarks (city, island, mountain)

d. Concrete entity: objects, artifacts (spear, chainsaw, axe)

e. Animate entity: animals (ant, dog, eagle), plants

f. (Pseudo-)sentient entity: higher animals, infants, Artificial Intelligence (chimpanzee, Deep Blue)

g. Anthropomorphic entity: entities human in appearance and groups thereof (humans, Poseidon)

\subsubsection{Autonomy}

The scales that aim to refine the General Animacy Scale are typically lumped together on a single axis, thereby greatly expanding it. This often leads to problems that require questionable solutions. For example, groups of people do not all pattern alike:

a. ???The mob carefully planned the assault.

b. The army brigade carefully planned the assault.

The example in (11b) is more acceptable than the one in (11a). ${ }^{5}$ The traditional approach would be to consider army brigade more animate than

$5 \quad$ I agree with Zaenen et al. (2004: 119) when they point out that as far as animacy differences are concerned, acceptability of a sentence is a more apt concept than 
mob. Therefore, so the argument goes, army brigade is more natural to use in conjunction with adverbs like carefully and verbs like plan. I do not agree with the idea that mob is less animate. In fact, as argument could be made that army brigade is 'less animate' because formal organizations can be considered dehumanized (cf. Yamamoto 1999: 20). I reject the idea that either of these is less animate than the other. What we have here - in both cases - are groups of people that are conceptualized as a collective. The crucial difference between them is that mob is inherently without internal organization, whereas armies and their constituent units are highly organized along formal lines. ${ }^{6}$ I believe it is more fitting to use the level of organization within a collective of people as a feature. This is a subsection of a hierarchy I call the Autonomy Hierarchy. It is necessary to introduce this hierarchy as an extra axis due to the shortcomings of the Silverstein hierarchy: Fauconnier (2011: 544), for example, stresses that the Silverstein hierarchy has difficulties capturing the semantic distinction between dependently and independently acting inanimates. ${ }^{7}$ Furthermore, the distinction between groups of animates is hard to capture with the hierarchy, as the mob and army brigade example illustrates. As far as typology is concerned, Dahl (2008: 142) points out that grammatical restrictions are often proposed in terms of cut-off points on a hierarchy. However, many phenomena are not reducible to a well-behaved hierarchy. Therefore, a system with two axes would allow for cut-off regions thereby greatly enhancing the explanatory power of animacy (in the broadest sense of the word).

Essentially, the autonomy hierarchy describes the referent's ability to perform an action independently. The higher a referent is located on the autonomy hierarchy, the less external manipulation it requires to perform the action in question. For instance, a knife requires more external manipulation to cut a loaf of bread to pieces than an electric knife. Therefore, knife will rank lower on the autonomy hierarchy than its more

grammaticality of sentences. That is to say, instead of categorical Yes vs. No judgments, the acceptability in this domain is very gradient.

6 A vaguely related distinction (collective voice/purpose) is used by Zaenen et al. (2004) as a tagging tool.

7 This distinction will prove to be crucial to capture the behavior of instruments and ISA. 
sophisticated counterpart. Placing actional independence on an axis of its own solves the problem of ranking these referents relative to each other in terms of animacy. This equally solves the dilemma of trying to distinguish a loose group of humans from a formally organized collective in terms of animacy (cf. Bresnan \& Hay 2008: 250). In my approach, both are equally animate but not equally autonomous.

Lakoff (1987) advocates an approach of radial categorization, whereby humans sit at the center and all other entities are at a distance. The more peripheral entities are located further away from the core, more humanlike ones are closer to the center. Unclear, however, is why - for example - supernatural beings are considered to be equally distant from the center as organizations like corporations. In my approach, a supernatural being like Poseidon would be considered as animate (i.e. anthropomorphic) like a normal human (e.g. Foe), but Poseidon would rank higher on the autonomy hierarchy. Important in Lakoff's (1987) approach, however, is the recognition of human-like machines. In the previous chapter, it was pointed out that more complex machines are better subjects than less complex ones. Also recall that internally powered machines are considered more animate than those with external power (Yamamoto 1999: 18). Rather than placing the explanation for this entirely on the animacy axis, I propose to use the autonomy hierarchy as a central explanatory tool. More complex machines or those with an internal power source are not more animate, but more autonomous.

Mechanisms are usually better candidates for 'agenthood', to use Schlesinger's (1989: 193) terminology, and, within the class of mechanisms, more complex and self-sufficient ones are 'better agents' than less complex and less self-sufficient ones (Schlesinger 1989: 197, 206-207). This seems to be true across languages (Alexiadou \& Schäfer 2006: 43-44 and own data):
a. $\quad$ Der
Kran hob
die
Kiste hoch.
DEF.NOM crane lift $\backslash$ PST.3G DEF.ACC crate up 'The crane picked up the crate.' (German)
b. ?Die Gabel hob die Kartoffel hoch.
DEF.NOM fork lift $P S T .3 S G$ DEF.ACC potato up 'The fork picked up the potato.' (own data) 
c. O geranos sikose to kivotio. DEF.NOM crane picked up DEF.ACC crate 'The crane picked up the crate.' (Modern Greek)

d. ${ }^{*}$ To piruni sikose tin patata. DEF.NOM fork picked up DEF.ACC potato 'The fork picked up the potato.' (own data)

e. De kraan til-de de kist op. DEF crane pick-PST.3SG DEF crate up 'The crane picked up the crate.' (Dutch)

f. ?De vork til-de de aardappel op. DEF fork pick-PST.3SG DEF potato up 'The fork picked up the potato.'

g. Sarah disabled Bill's computer with the hammer/the virus.

h. */?The hammer disabled the computer.

i. The virus disabled the computer.

j. Sarah sneed het brood in stukk-en Sarah cut $\mid$ PST.3SG DEF bread to piece-PL met het mes. with DEF knife 'Sarah cut the bread to pieces with the knife.'(Dutch)

k. ${ }^{*}$ Het mes sneed het brood in stukk-en. DEF knife cut $\backslash$ PST.3SG DEF bread to piece-PL 'The knife cut the bread to pieces.'

1. Sarah sneed het brood in stukk-en Sarah cut $\backslash$ PST.3SG DEF bread to piece-PL met het elektrisch mes. with DEF electrical knife 'Sarah cut the bread to pieces with the electrical knife.'

m. Het elektrisch mes sneed het brood in DEF electrical knife cut $\mathrm{PST} .3 \mathrm{SG}$ DEF bread to in stukk-en.

to piece-PL

'The electrical knife cut the bread to pieces.' 
To put this in line with my proposed approach: More complex mechanisms or appliances (e.g. those with electronic circuitry) rank higher on the autonomy hierarchy than simple inanimate objects like sticks or knives. Because of this, they are generally more acceptable in ISA. Mechanical machines occupy a middle position, as can be seen from the degree of acceptability:
a. Sarah beschadig-de de computer met de Sarah damage-PST.3SG DEF computer with DEF drilboor.
pneumatic drill

'Sarah damaged the computer with the pneumatic drill.' (Dutch)

b. ?De drilboor beschadig-de de computer. DEF pneumatic drill damage-PST.3SG DEF computer 'The pneumatic drill damaged the computer.'

c. Het computervirus beschadig-de de computer. DEF computer virus damage-PST.3SG DEF computer 'The computer virus damaged the computer.'

d. *De hamer beschadig-de de computer. DEF hammer damage-PST.3SG DEF computer 'The hammer damaged the computer.'

e. The lumberjack cut down the tree with the axe.

f. "The axe cut down the tree.

g. The lumberjack cut down the tree with the chainsaw.

h. ?The chainsaw cut down the tree.

i. $O$ ksilokopos ekopse to dentro DEF.NOM lumberjack cut down DEF.ACC tree me to tsekuri.

with DEF.ACC axe 'The lumberjack cut down the tree with the axe.' (Modern Greek, own data)
j. $\quad{ }^{*}$ To
tsekuri ekopse
to dentro. DEF.NOM axe cut down DEF.ACC tree 'The axe cut down the tree.' 
k. O ksilokopos ekopse to dentro DEF.NOM lumberjack cut down DEF.ACC tree me to alisopriono. with DEF.ACC chainsaw 'The lumberjack cut down the tree with the axe.'

1. ?To alisopriono ekopse to dentro.

DEF.NOM chainsaw cut down DEF.ACC tree 'The chainsaw cut down the tree.'

Not only mechanisms produce varying levels of acceptability, simpler objects do to. The examples in (14) all feature instruments that are not mechanical in nature.

(14) a. The assassin killed the man with the knife.

b. *The knife killed the man.

c. The assassin killed the man with the spear.

d. The spear killed the man.

e. The lumberjack cut down the tree with a saw.

f. The lumberjack cut down the tree with an axe.

g. ?De houthakker vel-de de boom met

DEF lumberjack cut down-PST.3SG DEF boom with een zaag.

INDEF saw

'The lumberjack cut down the tree with a saw.' (Dutch)

h. De houthakker vel-de de boom met

DEF lumberjack cut down-PST.3SG DEF tree with een bijl.

INDEF axe

'The lumberjack cut down the tree with an axe.'

It stands out that spear is a better candidate for ISA than knife. Contrary to a knife, a spear is specifically designed to kill. By contrast, knives have a wider array of functions such as cutting open boxes, applying butter to bread etc. Because of the spear's specific purpose, it ranks higher on the autonomy scale than knife. Likewise, the sentences in (14e) and (14g) are more marked than the ones in (14f) and (14h) because the referent axe is 
more compatible with cut down. This does not mean that (14e) and (14g) are ungrammatical, they are simply more marked.

I have illustrated that referents can intuitively be ranked on the autonomy hierarchy. How can this be formally captured? A gradual increase in autonomy correlates with an equally gradual increase in acceptability. Ergo, different levels of autonomy have to be distinguished. However, it would not suffice to posit mechanical vs. electronic vs. simple as dichotomies in the hierarchy. The reason for this is simple: It has been illustrated that there are acceptability differences within these categories as well, not only between them.

As far as mechanisms and self-motive entities are concerned, I propose a bifeatural analysis. The two features I propose are [ \pm independent] and $[ \pm$ controllable]. They are defined as follows:
a. A referent ranks as [+independent] iff the referent is potentially capable of independent action, i.e. action not immediately governed by another entity.
b. A referent ranks as [+controllable] iff the referent can be under control of another referent. ${ }^{8}$

Referents that are [-independent] are entities not capable of independent action. They are therefore always initiated or governed by another entity (i.e. [+controllable]). Examples of this category include cranes, printers, DVD-players and the like. They typically carry out relatively simple, direct orders given by a governing entity (such as a crane operator). Orders typically look like: "Move mechanical arm in direction of joystick's motion", "Print page 1", or "Play movie". The manipulation involved is less direct than with simple artifacts. For example, a chainsaw needs to be activated and held by a wielder, but the cutting motion is carried out by the machine itself. I will label this feature combination and referents fitting the description as semi-autonomous. I not only recognize mechanisms as being semi-autonomous or higher, but also chemicals or medication. These have to be administered or deployed by a

8 What is controllable is judged from the perspective of humans (i.e. anthropocentric). 
manipulator, but then function according to the purpose they were designed for (curing a headache, for instance). Consider:

a. The acid ate away at the lock.

b. The aspirin cured his headache.

Referents that are [+independent] and [+controllable] are entities that can act on their own, but within the framework of carrying out instructions. These instructions are typically more complex and require (at some stages in the process) independent decision making on the part of the governed entity. An excellent example here is any object that has some degree of AI. A computer virus is intended and initiated by a governing entity to wreak havoc on a target. In the process of wreaking havoc (of whatever nature), the program will have to make independent decisions on how to progress without the governing entity being able to intervene. I will call this combination of features autonomous. It is clear to me that there are huge differences within the field of AI as far as the degrees of autonomy are concerned. Yet, I do not think these are relevant to the average speaker's conceptualization of AI. In fact, AI's decision making abilities often cause it to pattern with humans, despite clearly being inanimate. Dabrowska (1998: 124) points out that nouns from this domain tend to be assigned more human traits than typical inanimate tools. They are considered to be capable of malice, amongst others (Rosenbach 2008: 155). Consider the following sentences that have been uttered to me in the context of videogames:
a. De AI deed
dat
met opzet! ${ }^{9}$
DEF AI do\PST.3SG DEM.OBJ on purpose
'The Artificial Intelligence unit did that on purpose!'
(Dutch)
b. De AI heef-t blijkbaar een plan.
DEF AI have-PRS.3SG apparently INDEF.OBJ plan.
'Apparently, the AI unit has a plan.'

\footnotetext{
9 In Dutch, in contrast to English, $A I$ can refer to a single unit of artificial intelligence. To make the English translation more sensical, I have opted to translate $A I$ as AI unit.
} 
Both sentences in (17) attribute human or quasi-human traits to an inanimate but intelligent program. Doing something on purpose is certainly the product of intention (and in this case also malice) and having a plan is a sign of decision making abilities. Despite the inanimate nature of the referents, both examples are grammatical and acceptable. Humans are also considered to be autonomous. They do rank higher than instances of AI because humans are more mobile due to their having limbs that can interact with the real world. By contrast, most entities endowed with a form of artificial intelligence are confined to storage facilities of some sort.

A referent that is [+independent] and [-controllable] is a typical forceeffector, such as a storm or a meteor shower. These referents act independently and cannot be controlled by another entity. This is evidenced by the unacceptability of the sentences in (18).

\section{a. 'John wrecked his neighbor's yard with a meteor shower. \\ b. $\quad{ }^{*}$ Eric used the storm to cut down the tree.}

I propose to label this combination of features as para-autonomous. Despite what the terminological background might suggest, referents that are [-independent] and [-controllable] do exist. They cannot act independently, but cannot be controlled either. These are usually parts of an interconnected system beyond conscious human control, such as organs. They are, as it were, interdependent. As such referents cannot be consciously controlled, they can never be instruments and are therefore not relevant for the current discussion (they are marked accordingly in the table). I have summarized this in table 15:

\begin{tabular}{l|l|l} 
& {$[+$ controllable $]$} & {$[$-controllable $]$} \\
\hline$[+$ independent $]$ & Autonomous & Para-autonomous \\
\hline$[$-independent $]$ & Semi-autonomous & Irrelevant
\end{tabular}

Table 15: Feature matrix for the principal levels of autonomy.

More importantly, it is possible to visualize these distinctions in a scalar way: para-autonomous ranks highest, semi-autonomous ranks lowest 
and autonomous ranks in the middle. This fits the intuition that entities that sometimes need control rank lowest, referents that do not have be to controlled rank above those, and entities that cannot be controlled rank highest.

The distinctions above do not apply to those referents that must be controlled directly or continuously by a wielder due to their inherent properties. Simple artifacts like knife and axe do not carry out instructions like semi-autonomous referents. Rather, they are continuously and directly manipulated by the wielder. In other words, they do not fall into this schema. It would be erroneous to assume that knife also ranks as [+controllable]. [+controllable] means that a referent can be controlled, but does not have to continuously or directly. With simple artifacts, however, a manipulator must exercise a form of control directly and continuously. For example, the difference between a knife and an electrical knife is that the latter does the cutting action by itself as the blade moves by itself. The manipulator guides it in the process. By contrast, a simple knife requires the user to move it and make the cutting motion in order for it to cut. I consider such referents as ranking beneath semiautonomous. I term all referents below semi-autonomous as nonautonomous.

It is possible to make a distinction within this class. Here my account is vaguely inspired by Alexiadou \& Schäfer's (2006) concept of 'grounded property'. They do not define this feature, nor do they treat it consistently (see chapter 3). I do believe, however, that there is some relevance to it. Consider:

(19) a. John unlocked the door with the key.

b. John unlocked the door with the stick.

c. Pierre spliced open the boulder with a knife.

d. Pierre spliced open the boulder with a pick-axe.

Even though all sentences are grammatical, (19a) and (19d) are more acceptable and more natural. This is because in those two examples the instrument is specifically designed for the action described by the verb. I therefore propose to rank specifically tailored referents above plain artifacts. This also fits the idea of manipulation as the inverse of autonomy. 
Cutting a cake with a stick will require more lengthy manipulation on the part of the instigator than with a knife, as the latter was specifically designed for the cutting activity, requiring less total effort.

The borders between the echelons of the autonomy axis are not always clear. Similarly to animacy (cf. Yamamoto 1999), I propose to treat these categories as fluid and gradient. For example, knives are very multifunctional. Therefore, it is not always clear whether they are to be considered as a higher-level plain artifact or as a specifically tailored object.

The complete autonomy hierarchy is given below in (20). Autonomy can be considered the inverse of manipulation: The lowest levels must be manipulated by a manipulator. The higher a referent is located, the less manipulation it requires, until a level is raeched where the referent cannot be manipulated. Echelons (1-2) taken together are considered nonautonomous and echelons (4-7) are considered to be autonomous.

$$
\begin{aligned}
& \text { plain artifact }(1)<\text { specifically tailored }(2)<\text { semi-autonomous (3) } \\
& <\text { autonomous (proper) }(4) \text { < group (5) < organization (6) } \\
& \text { < hive/individual human }(7)<\text { para-autonomous (8) }
\end{aligned}
$$

In the previous section, levels of organization and groups were discussed in relation to the autonomy hierarchy. Since humans and groups of humans rank as autonomous, I have introduced the relevant distinctions in the autonomous class.

\subsubsection{The actionality scale}

Similar to proposals found in the literature, the animacy hierarchy that I proposed is egocentric and anthropocentric. The autonomy hierarchy, on the other hand, is not anthropocentric (even though the terminology might be): Humans are not the highest level. This allows for a very natural ranking of referents such as meteor shower or storm: They are more autonomous than humans but not animate. This 2-dimensional characterization does the inherent features of referents more credit than the traditional, one-dimensional animacy hierarchies.

The combination of the animacy hierarchy and the autonomy hierarchy yields an axis-system. An axis-system allows for a cluster-wise identification of (groups of) referents, rather than forcing them on a 
one-dimensional line. Forces, for instance, pattern in a very specific portion of the axis system (figure 35). This 2-dimensional clustering provides the benefit of identifying specific zones, similar to Grimm's lattice system. If the referent is within the portion of semantic space as required by the verb (logical structure), it will be able to occupy that LS-position. The animacy axis was loosely inspired by Van Valin \& Wilkins (1996). ${ }^{10}$

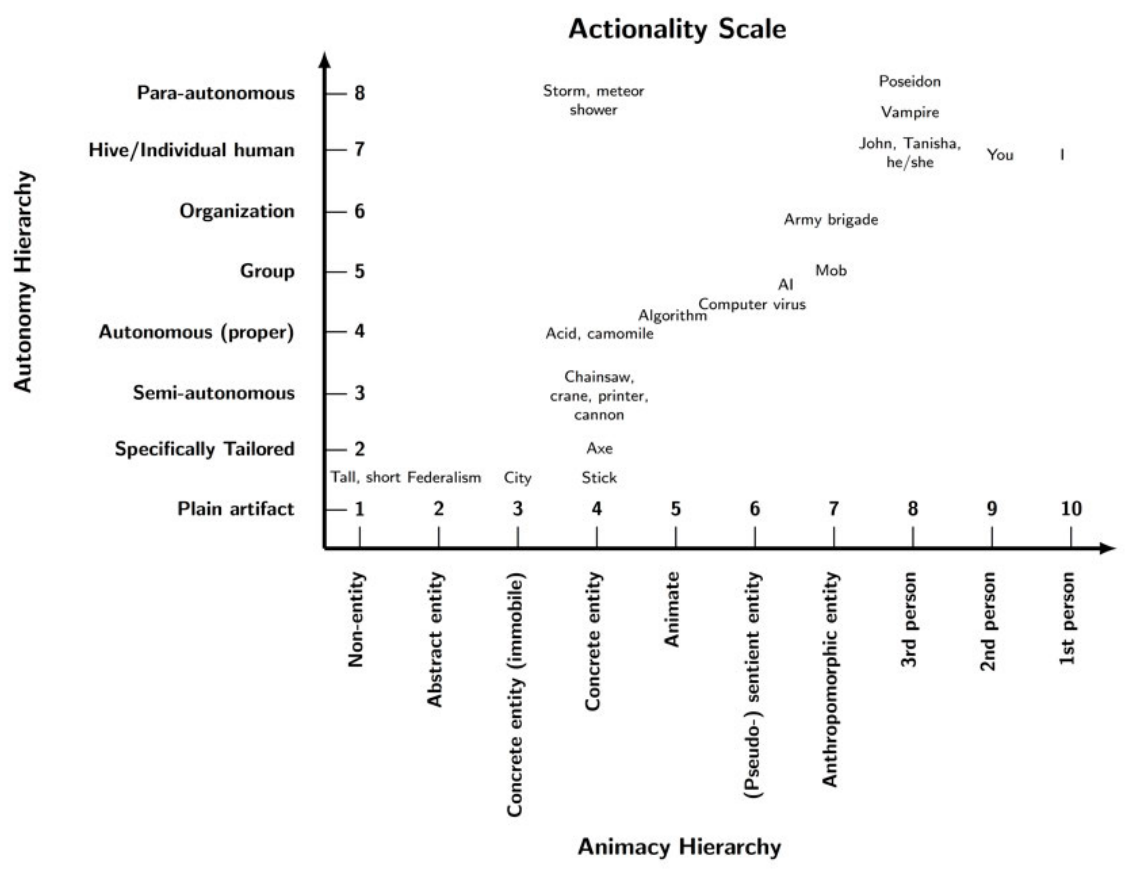

Figure 35: The actionality scale with example referents.

The graph in figure 35 represents the actionality scale with several examples. Do note that this graph is mainly intended for illustration purposes. Due to limitations on graphical representation, the referents' position should be treated as approximate and not as absolute.

10 For instance, the notion of non-entity was adopted from Van Valin \& Wilkins (1996). 
RRG's AUH-approach illustrates that structurally higher positions tend to be occupied by more animate entities (de Swart et al. 2008: 134). The actionality scale can be seen as a more elaborate version of this idea: Certain regions in the scale tend to correlate with certain argument positions.

\subsubsection{Pseudo-agents}

In the previous sections, it has become clear that the traditional concepts of instrument, force and agent correlate with certain areas on the actionality scale. The gradience of the scale suggests that there might be referents that can be conceptualized as both instruments and instigators in their own right. Consider:

(21) a. John sprayed the fields with the piper plane. (after

Schlesinger 1989: 193)

b. $\quad$ The piper plane sprayed the fields. (Schlesinger 1989: 193)

c. The piper plane sprayed the fields with the wing-mounted spray guns.

d. John picked up the crate with the crane.

e. The crane picked up the crate. (adapted from Schlesinger 1989: 193)

f. The crane destroyed the house with a big boulder.

g. The hacker disabled fohn's computer with a computer virus.

h. The computer virus disabled John's computer by means of an algorithm.

i. $\quad$ Mara destroyed the village with the tank.

j. The tank destroyed the village with one artillery shell.

I assume that referents have to be within the correct portion of space in figure 35 for them to be realized as an instigator or an instrument. For instance, the referent knife does not occupy the correct area on the scale to allow a realization as an instigator. As the referents in question are inanimate, an obvious step in a classification is to distinguish forces from instruments by testing. To do this, I propose two sets of tests. The first involves isolating the referent's ability to occupy certain LSpositions: (1) Use the referent as an instigator using another instrument 
and (2) use the referent as an instrument. These tests correspond to positions in the logical structure. Hence, 'use as an instrument' means that the referent is inserted into an intermediate effector position. Consider the examples in (22).

(22) a. John destroyed the barn with the sledgehammer.

b. $\quad$ "The sledgehammer destroyed the barn with the boulder.

c. The storm destroyed the barn with its strong winds.

d. * Fohn destroyed the barn with the storm.

Sledgehammer fails test (1) but passes test (2), making it an instrument. Storm passes test (1) but fails test (2) making it a force. I have summarized the tests proposed by Van Valin \& Wilkins (1996) in the table below. ${ }^{11}$

\begin{tabular}{l|l|l} 
& Use as instigator (1) & Use as instrument (2) \\
\hline Force & Yes & No \\
\hline Instrument & No & Yes
\end{tabular}

Table 16: Tests to distinguish instruments from forces.

The previous sections have illustrated, however, that animacy and autonomy are gradient notions. This predicts the existence of referents that pass both these tests and thus belong to what Yamamoto (1999: 18) calls 'borderline cases'. As was pointed out before, typical instances include intelligent machines. Consider (23).

11 These tests obviously have to be adapted to the fit language under investigation. Japanese, for instance, does not allow any inanimates in subject position (Kuno 1973: 31), thereby making test (1) unusable. 
a. Mara breached the firewall with the cleverly constructed computer virus.

b. Het computer virus doorboor-de de firewall DEF computer virus breach-PST.3SG DEF firewall met afvalbestand-en. with junk file-PL 'The computer virus breached the firewall with junkfiles.' (Dutch)

c. Peter assembled the car by means of the assembly robot.

d. The assembly robot assembled the car with a screwdriver.

In the examples in (23), the referents pass both tests. It follows therefore, that these borderline referents can be instruments or instigators. Generally, there are two subtypes of instigating effectors, forces and agents. Forces themselves can be distinguished from agents by the fact that the former are inanimate. The second diagnostic is intended to see how a referent patterns and to determine what type of instigator they are most similar to: a force or an agent. To do this, I propose a test that isolates the para-autonomous feature that uniquely defines forces (the controltest). That is to say, they are conceptually uncontrollable. Humans (the most prototypical agents) rank as autonomous because they can be controlled. If a referent tests as controllable, then it is more like an agent. If it is uncontrollable, it patterns with forces. Verbs like command or order or causative auxiliaries entail a form of control on the part of the controller with respect to the controllee. Consider the following examples with their Dutch ${ }^{12}$, German and French equivalents:
a. Mara commanded the computer virus to attack the mainframe.
b. Mara made the computer virus attack the mainframe.

12 The Dutch examples in (24h) and (24j) use a form of the verb doen. This is typical of Belgian Dutch (Heine \& Kuteva 2006: 60. Also see Taeldeman (1978: 60), in contrast to Netherlandic Dutch, which prefers to use laten (let) to express all types of causation (also see chapter 5). Belgian Dutch has two causative verbs (doen and laten) expressing different types of causation. In this respect, Belgian Dutch is more similar to French and Netherlandic Dutch is more similar to German. All Dutch examples in this thesis are from Belgian Dutch, unless explicitly indicated. 
c. Mara commanded Bill to attack Pat.

d. Mara made Bill attack Pat.

e. ??Mara commanded the storm to back down.

f. ??Mara made the storm back down.

g. Mara beval de AI de mainframe

Mara order|PST.3SG DEF AI DEF mainframe

aan te vallen

to attack.INF (Dutch)

h. Mara deed de AI de mainframe aanvallen.

Mara dolPST.3SG DEF AI DEF mainframe attack.INF

i. ??Mara beval de storm te gaan liggen.

Mara order|PST.3SG DEF storm to go.INF lie.INF

j. ??Mara deed de storm gaan liggen.

Mara do\PST.3SG DEF storm go.INF lie.INF

k. Mara befahl der KI den Mainframe anzugreifen.

Mara order\PST.3SG DEF AI DEF mainframe attack

(German)

1. Mara lie $\beta$ die KI den Mainframe angreifen.

Mara let PST.3SG DEF AI DEF mainframe attack.INF

m. ??Mara befahl dem Sturm sich zu legen.

Mara order\PST.3SG DEF storm REFL to lie.INF

n. ??Mara ließ den Sturm sich legen.

Mara let\PST.3SG DEF storm REFL lie.INF

o. Mara a commandé au virus d'attaquer

Mara AUX.3SG order.PTCP to.the virus to=attack

l'unité central.

$\mathrm{DEF}=$ mainframe (French)

p. Mara a fait attaquer l'unité central

Mara AUX.3SG do.PTCP attack.INF DEF=mainframe

par le virus.

by DEF virus 
q. ??Mara a commandé à la tempête

Mara AUX.3SG order.PTCP to DEF storm

de reculer.

to recede.INF

r. ??Mara a fait reculer la tempête.

Mara AUX.3SG do.PTCP recede.INF DEF storm

The examples in (24a-24f), $(24 \mathrm{~g}-24 \mathrm{j}),(24 \mathrm{k}-24 \mathrm{n})$ and $(24 \mathrm{o}-24 \mathrm{r})$ show that the borderline cases pattern with agents rather than with forces. This confirms the provisional ranking of referents in figure 35 where they are closer to humans than to forces.

I will term these borderline referents pseudo-agents because they can be conceptualized by speakers as either instigators or instruments. One might wonder why I do not simply label them 'agents'. There is a principled reason for this: Despite being closer to agents than to forces, there are still some differences between pseudo-agents and agents. Pseudoagents rank lower in sentience than humans, as is illustrated by the examples below:

a. John grudgingly blew up the barn.

b. ??The computer virus grudgingly disabled the firewall.

c. Jan blies tegen zijn zin de

Jan blow up\PST.3SG against POSS wish DEF schuur op.

barn VPR

'Jan blew up the barn against his will.' (Dutch)

d. ??De AI schakel-de tegen zijn zin de

DEF AI switch-PST.3SG against POSS wish DEF firewall uit.

firewall off

'The AI switched off the firewall against its will.'

Due to their lower sentience, the subject referents in (25b) and (25c) do not pattern with adverbs expressing emotional states too well. As animacy is inherently anthropocentric, emotional faculties are associated with higher animacy. Conversely, entities incapable of emotion (in the 
broadest sense of the word) will be ranked lower. Rather than treating pseudo-agents as a new effector type, they are a class of referents that can be conceptualized as either instruments or instigators. For this reason, the range of pseudo-agents has been indicated with a dashed line in figure 37. It is most interesting to find that a power differential manifests itself:

(26) a. The computer virus destroyed the firewall by means of the algorithm.

b. The algorithm destroyed the firewall by means of a set of junk files.

c. $\quad$ The algorithm destroyed the firewall with the computer virus.

d. De AI leg-de het gegevenscentrum met DEF AI cripple-PST.3SG DEF data center with het virus lam. DEF virus VPR

e. Het virus leg-de het gegevenscentrum DEF virus cripple-PST.3SG DEF data center met een reeks junkbestand-en lam. with INDEF series junk file-PL VPR

f. ${ }^{*}$ Het virus leg-de het gegevenscentrum DEF virus cripple-PST.3SG DEF data center met de AI lam. with DEF AI VPR

In the examples (26a-26c) and (26d-26f), both relevant referents (computer virus \& algorithm and AI \& virus, respectively) can each be conceptualized as an instigator, as the first two sentences of each set show. However, the lower-ranking referent cannot be the instigator over a higher-ranking one, as the third sentence in each set shows. An algorithm is less sophisticated than a computer virus and a virus is less advanced than $A I$. This would place $A I$ highest on the actionality scale, virus second highest and algorithm lowest. This principle can be formalized as the Relative Power Principle. 
(27) Relative Power Principle (preliminary): The instigating referent must be ranked higher on the actionality scale than the intermediate effector referent.

In most situations, however, this is unproblematic, as there is a clear scale difference between a human wielder and, say, a hammer. It is potentially difficult in cases where both referents are similarly ranked and when both can occupy both positions in the logical structure. A word of caution is in order here. It would be erroneous to equate pseudo-agents with those instruments that can undergo ISA. Knife, for instance, can never occupy the instigator position, but can undergo ISA in English. It is likely that all pseudo-agents can undergo ISA, but not all instruments that can undergo ISA are pseudo-agents.

Where are pseudo-agents located in semantic space, then? I contend that a referent must rank as autonomous (proper) on the autonomy hierarchy but must not exceed level 5 (group) to be a pseudo-agent. The black arrow in figure 36 denotes the upward direction of the actionality scale.

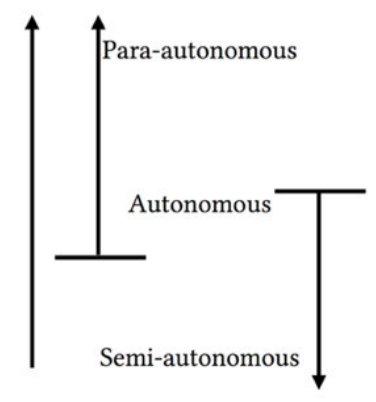

Figure 36: Semantic space of pseudo-agents.

It is now possible to indicate the portions of semantic space where forces, instruments, agents and causees are prototypically located. Pseudoagents have simply been indicated with a dashed line and without a label, so as to make clear that I do not consider them as an effector type. As I have illustrated, there are areas where these concepts overlap (see figure 37). 
The delineation indicated by the oval shapes is not absolute. I have stressed throughout this dissertation that animacy and related concepts are subject to gradience and fluidity. This holds for the partitioning of semantic space in figure 37 as well.

As a consequence of compounding animacy and autonomy into the actionality scale, references to 'animacy' no longer suffice to characterize the difference between forces, instruments, agent, causees and the like. Instead, their positions in semantic space would ideally be indicated by way of coordinates in a Cartesian axis system. This is obviously a very technical matter and I will go into it in section 4.3.

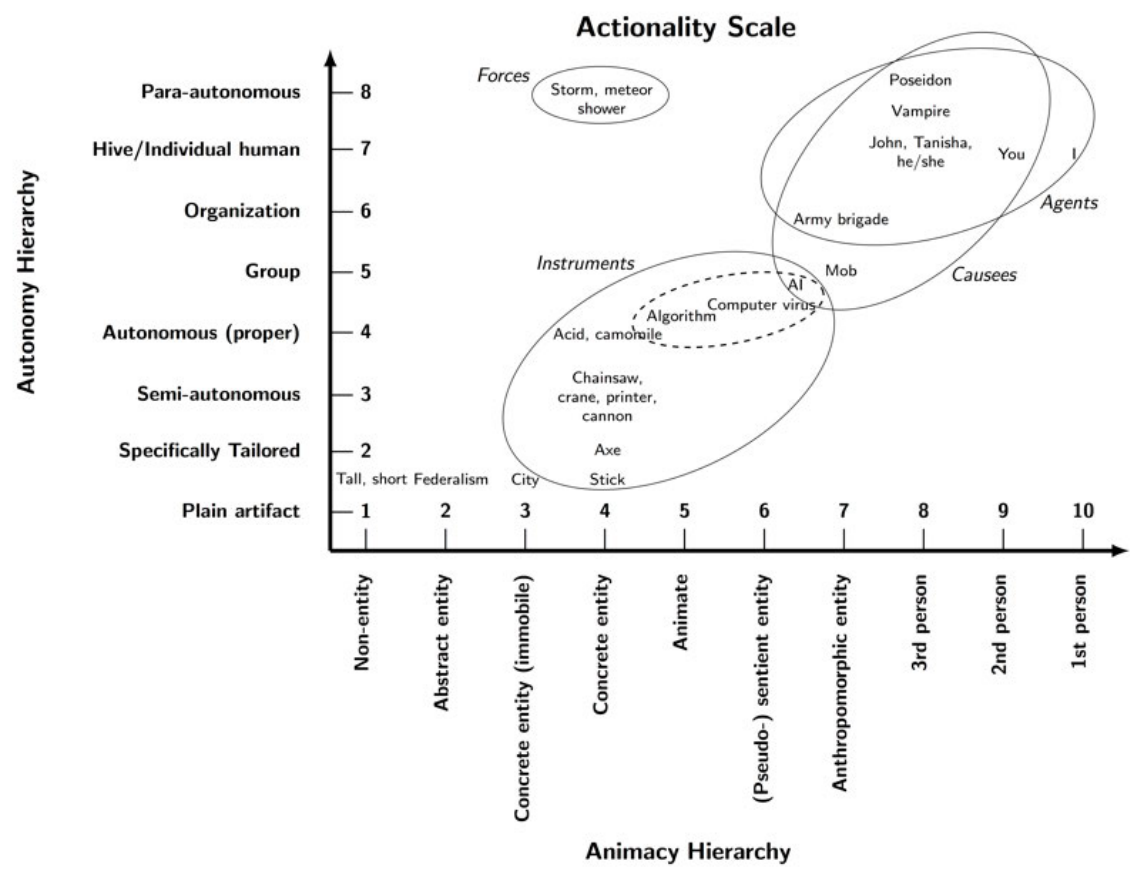

Figure 37: Range of instruments, forces, agents, pseudo-agents and causees within the actionality scale.

On a (very) minor note, one colleague pointed out that typical force arguments like storm can sometimes be used as instruments. For example: 
(28) a. Poseidon sank the fleet with/by means of the storm.

b. Poseidon used the storm to sink the fleet.

Two remarks are in order here: 1) These are very uncommon utterances and 2) they are part of a fictitious setting in which storm and similar referents are commonly personified ((29a, 29b)).
a. Poseidon sent the storm to destroy the fleet and it obeyed.
b. Poseidon ordered the storm to destroy the fleet and it obeyed.

Even if one were to accept the sentence in (28) as normal everyday language, then acceptability is conditioned by the status differential between instigator and instrument. Within mythology, Olympic deities are considered more powerful than natural phenomena.

\subsubsection{Inherent vs. induced features}

DeLancey (1984: 203ff.) and Levin \& Rappaport Hovav (2005: 49), amongst others, point out that objects typically functioning as instruments can occur in subject position without actually being manipulated by an instigator. The axe in the axe broke the window (DeLancey 1984: 203) can be construed as falling due to natural circumstances, say, the referent falling off a shelf. However, such eventive construals require considerable context (Levin \& Rappaport Hovav 2005: 49). This observation usually entails an inanimate object being imbued with some kind of kinetic energy (Cruse 1973: 16, 19). For instance, by adding the adjective herunterfallend ('falling down') to Axt ('axe') in German, it becomes more acceptable as a subject. Consider:

a. Die herunterfallende Axt zerbrach
DEF.NOM falling-down axe broke
die $\quad$ Scheibe.
DEF.ACC window pane
'The falling axe broke the window pane.'
(Alexiadou \& Schäfer 2006: 44)


b. ${ }^{*}$ Die Axt zerbrach die Scheibe.

DEF.NOM axe broke DEF.ACC window pane

'The axe broke the window.' (Alexiadou \& Schäfer 2006:

44)

c. ?De steen heeft de ruit gebroken.

DEF rock AUX DEF window break.PTCP

'The rock broke the window.' (Alexiadou \& Schäfer 2006: 44)

d. De vliegende steen heeft de ruit gebroken. DEF flying rock AUX DEF window break.PTCP 'The flying rock broke the window.' (Alexiadou \& Schäfer 2006: 44)

e. $\quad{ }^{*}$ The gun killed the general. (own data)

f. The bullets killed the general.

These are clear examples where the referent is imbued with kinetic energy making it eligible for a position (subject) that it is usually not eligible for. The properties in question can be considered to be induced, as falling is not an inherent property of an axe, nor is it an inherent feature of rocks to fly. In (30f) world knowledge will dictate the bullets have been fired and were in flight. The introduction of such properties has a profound influence on argument linking. In the examples in (31), the predicate requires the object to be able to move, yet the induced feature (parked) makes the RP incompatible with the verb's requirements:

a. William drove away in the car.

b. ${ }^{*}$ William drove away in the parked car.

I believe that adnominal modification, modification by clauses and the like can be captured with the actionality scale. Rather than conceding such examples as overrides of normal examples or exceptions to the rule, I propose to directly include them in the actionality scale-approach.

I assume that referents have inherent properties. A car, for example, has the inherent property that it can move (see Barsalou 1992 for the conceptualization of a car in human cognition) amongst others. A key has the inherent ability to open a door due to the specific configuration 
of grooves it was designed to have (provided the target lock has the matching configuration). These properties place the referents somewhere on the actionality scale. If a feature or property is induced, the new feature matrix of the referent will assign it a new position on the scale. This in turn makes it (potentially) eligible to fill argument positions in the logical structures that it could otherwise not fill. The opposite is also possible: The introduction of a feature may move a referent to a location in the hierarchy that is outside of accessible semantic space, as the example in (31b) illustrates. If there is no information specifying otherwise, only the inherent features of a referent are relevant for linking. The examples above contained phrase-level modification. Whereas this is a very straightforward strategy to induce features, others do exist. For instance, it is possible to include modifying subordinate clauses. Consider:

(32) a. As a result of the explosion, a stone flew across the road and broke the window. (Cruse 1973: 20)

b. */?A stone flew across the road and broke the window.

The subclause in (32a) changes the feature matrix, thereby raising the referent on the scale to a position within the accessible area of fly's effector argument. Without the modifying subclause, the sentence would not be acceptable as (32b) illustrates.

This mechanism holds for all referents in relation to the argument positions of a given verb. Ergo, it is also relevant for instruments and ISA. Consider the following Dutch examples:

a. Jan dood-de de vogel met het mes. Jan kill-PST.3SG DEF bird with DEF knife 'Jan killed the bird with the knife.'

b. *Het mes dood-de de vogel. DEF knife kill-PST.3SG DEF bird '*The knife killed the bird.' 
c. Jan dood-de de vogel met het mes Jan kill-PST.3SG DEF bird with DEF knife dat hij gooi-de.

REL 3SG throw-PST.3SG 'Jan killed the bird with the knife that he threw'.

d. Het mes dat fan gooi-de dood-de

DEF knife REL Jan throw-PST.3SG kill-PST.3SG de vogel.

DEF bird

'The knife that Jan threw killed the bird.'

Normally, the verb kill selects an x-argument from a portion of semantic space that knife is not in. However, with the induction of kinetic energy in the form of RP-level modification, the referent is 'moved' to the portion of semantic space that is accessible to kill's effector argument. Sentences such as (33c-33d) are the inevitable counter-examples to any theory of instruments and ISA. My approach has the advantage that such additional information is handled with the same mechanism. It is often pointed out by my informants that typical instruments as subjects are perfectly acceptable in fairy-tale like contexts or if the instrument is personified. Consider:
a. ?Nozh
razrézal
hleb.
knife.NOM.SG cut.PERF.PST.3SG.M
bread.ACC.SG.M
'The knife cut the bread.' (Russian)
$\begin{array}{llll}\text { b. } & \text { ?Nož je sekao hleb. } \\ \text { knife.NOM AUX.3SG cut.PTCP bread.ACC }\end{array}$
'The knife cut the bread.' (Serbian)
c. ?Peilis pjov-e duon-a.
'The knife cut the bread.' (Lithuanian)
knife.NOM cut-PST.3SG bread-ACC.SG

The sentences in (34) are ungrammatical, except if the knife is personified. Informants report that in such cases the knife is considered a selfmoving, reasoning entity. The same is true for Dutch. As Rosenbach (2008: 155) points out, animacy is not a fixed category but can be 
tweaked. That is to say, referents can be moved along the hierarchy to a different position. In my view, feature induction is just that: Moving the referents on the actionality scale by introducing certain features or stripping the referents of them.

In fact, personification of lower animates or inanimates is recognized in the literature (cf. Yamamoto 1999: 12-13). In my approach, personifications or anthropomorphizations can be captured with essentially the same mechanics as described above: Features are introduced into the feature matrix of the referent, giving it a different position on the scale. I propose to treat personifications as an extreme form of feature induction.

\subsection{The prevalence of instruments and implements with respect to verb classes}

In this section, I explore the prevalence of instruments and implements ${ }^{13}$ with respect to the verb classes recognized by RRG. To do this, I will take canonical examples for each of these classes (adapted from Van Valin 2005: 46-47) and determine whether they allow for instruments and implements by adding these to the base structure. My prediction is that instruments can only be added to causative verb classes, as the very notion of instrument is defined over causation. However, implements are not dependent on causation and therefore they should be admissible in more cases. Implements are necessarily under the scope of a do'predicate (Van Valin 2005: 55). Therefore, they should only be able to appear in LSs that have a do'-component.

First, let us explore states. As expected, adding a with-PP is inadmissible with any kind of instrumental reading. Consider examples from English, Dutch, German and French in (35).

13 As implements have not yet been explored in greater detail, all implements mentioned in this section follow standard RRG-assumptions. 

a. ?Pat is a fool with a knife.
b. ?Pat is een idioot met een mes. Pat be.PRS.3SG INDEF idiot with INDEF knife (Dutch)
c. ?Pat ist ein Idiot mit einem Messer. Pat be.PRS.3SG INDEF idiot with INDEF knife (German)
d. ?Pat est idiot avec un couteau.
Pat be.PRS.3SG INDEF idiot with INDEF knife (French)

These sentences are only acceptable if the with-PP is interpreted as expressing an attribute of Pat. The attribute reading of with-PPs is explored further in chapter 7 . Some states do not combine with a with-PP in any form, as (36) illustrates.

(36) a. *The cup is shattered with a rock.

b. ???Dana saw the mountain with binoculars.
c. ???Dana zag de berg met
Dana see\PST.3SG DEF mountain with een verrekijker.

INDEF Binoculars(SG) (Dutch)

d. The cup has been shattered with a rock.

e. Dana looked at the mountain with binoculars.

f. $\quad{ }^{*}$ Dana acted on the binoculars acted causing them to see the mountain.

g. do' (Dana, [see' $($ Dana, mountain $) \wedge$ use $^{\prime}($ Dana, binoculars)])

The sentence in (36a) is inadmissible. The variant in (36d) is not a counterexample. Rather, it is a causative achievement that has been passivized. I will go into the passivization of sentences containing an instrument in chapter 8. (36b) and (36c) are equally inadmissible. Note, however, that look at allows for the with-PP (36e) as it is an activity predicate with an implement under the scope of do'. It is not an instrument, because it fails the paraphrase in (36f). Therefore, (36e) corresponds to the LS in (36g). 
Activities should readily allow for implements, as they have a do' in their LS. The example in (3.84b) is an activity predicate with an implement. Yet, not every activity predicate allows for an implement:
a. $\quad$ "The children cried with balloons.
b. ${ }^{*}$ De kind-eren ween-de-n met ballonn-en.
DEF child-PL cry-PST-3PL with balloon-PL (Dutch)
c. ${ }^{*}$ Die Kinder wein-te-n mit Ballon-s.
DEF child-PL cry-PST-3PL with balloon-PL (German)
d. *Les enfants pleuraient avec des ballons. DEF child.PL cry.PST.3PL with INDEF balloon.PL (French)

This is due to the finer-grained semantics of cry. It is of such a nature that there is no tool that can possibly influence the activity. The contrast between (3.84b) and (37) shows that implements influence the activity in question in a facilitating manner: The activity is made easier for the user of the implement.

Achievements, stative semelfactives and accomplishments do not allow for implements or instruments, as their LS would predict. Consider the following examples with their Dutch equivalents.

(38) a. "The window shattered with a rock.

Achievement

b. ${ }^{*}$ De ruit verbrijzel-de met een steen.

DEF window shatter-PST.3SG with INDEF rock

c. ?Dana glimpsed the mountain with binoculars Semelfactive

d. ?Dana ving een glimp op van Dana catch $\backslash$ PST.3SG INDEF glimpse VPR of de berg met de verrekijker. DEF mountain with INDEF binoculars(SG)

e. $\quad$ Dana acted on the binoculars, causing them to glimpse the mountain. 
f. ${ }^{*}$ Dana werk-te op de verrekijker in en dat Dana act-PST.3SG on DEF binoculars VPR and CNJ veroorzaak-te dat hij glimp een cause-PST.3SG CNJ 3SG glimpse INDEF van de berg opving. of DEF mountain catch $\backslash$ PST.3SG

g. SEML see' (Lauren, mountain) $\wedge$ do' (Lauren, [use' (Lauren, binoculars)])

h. SEML see' (Lauren, mountain) $\wedge$ do' (Lauren, [use' (Lauren, verrekijker)])

Semelfactives only peripherally allow for implements ((38c-38d)), as evidenced by their marginal acceptability. The failure of the paraphrases in (38e-38f) identifies these tools as implements, corresponding with the LSs in (38g-38h).

Active accomplishments readily allow for implements, as is to be expected ((39a-39b)).
a. Chris liep naar het park met Chris run\PST.3SG to DEF park with loopschoenen.

Running shoes-PL

'Chris ran to the park with running shoes.' (Dutch)

b. Carl ate the pizza with a fork.

c. do' (Chris, [run' (Chris) $\wedge$ use' $($ Chris, loopschoenen)]) $\&$ INGR be-at' (park, Chris)

d. do' $($ Carl, [eat' $($ Carl, pizza) $\wedge$ use' $($ Carl, fork)] $\&$ INGR consumed' (pizza)

e. ${ }^{*}$ Chris werk-te op de loopschoen-en in Chris act-PST.3SG on DEF running shoe-PL VPR en dat veroorzaak-te dat ze het park CNJ REL cause-PST.3SG CNJ 3PL DEF park bereik-t-en. reach-PST-3PL

f. $\quad{ }^{*}$ Carl acted on the fork, causing it to eat the pizza. 
The tools in (39a) and (39b) are implements as they fail the causative paraphrase that identifies instruments $((39 \mathrm{e}-39 \mathrm{f}))$. Now we turn to the causatives, which, according to RRG-theory, should allow for instruments. Causative states allow for instruments, as (40) illustrates. The causative paraphrase is passed, revealing the LSs in (40e) and (40f).
a. $\quad$ The man scared the dog with the stick. ${ }^{14}$
b. The man acted on the stick, causing it to scare the dog.
c. Der Mann verängstig-te den Hund mit DEF man scare-PST.3SG DEF dog with einem Stock.
INDEF stick (German)
d. Der Mann wirk-te auf den Stock
DEF man act-PST.3SG on DEF stick
ein welcher den Hund verängstig-te.
VPR REL DEF dog scare-PST.3SG
e. $\quad\left[\right.$ do' $\left.^{\prime}(\operatorname{man}, \varnothing)\right]$ CAUSE $\left[\left[\right.\right.$ do' $^{\prime}($ stick, $\left.\varnothing)\right]$ CAUSE $\left[\right.$ feel $^{\prime}$ (dog, [afraid'])]]
f. $\quad\left[\right.$ do' $^{\prime}($ Mann, $\left.\varnothing)\right]$ CAUSE $\left[\left[\right.\right.$ do' $^{\prime}($ Stock, $\left.\varnothing)\right]$ CAUSE $\left[\right.$ feel $^{\prime}$ (Hund, [afraid'])]]

The examples in (40) can be interpreted as the man hitting the dog with the stick, causing it to be scared. However, it is also possible that there is a more indirect causal relation between the stick and the dog's being scared. For instance, the dog can be scared by the man throwing the stick in front of it or by man wildly swinging it around. Less direct forms of causation are explored in chapter 5 .

Causative activities also allow for instruments:
a. Felix bounced the ball with the oar.
b. Felix acted on the oar, causing it to bounce the ball.

14 The original in Van Valin (2005: 47) has a dog scare a boy. An instrument here would be somewhat less acceptable because of the dog's limited potential to wield instruments. In actionality terms, dog would be too low on the scale to occupy the instigator position of the expanded LS. 
c. $\quad\left[\mathbf{d o}^{\prime}(\right.$ Felix, $\left.\varnothing)\right]$ CAUSE $\left[\left[\mathbf{d o}^{\prime}(\right.\right.$ oar, $\left.\varnothing)\right]$ CAUSE [do' (ball, [bounce' (ball)])]]

d. Felix deed de bal bots-en met Felix do\PST.3SG DEF bal bounce-INF with de roeispaan.

DEF oar

e. Felix werk-te op de roeispaan in, wat er Felix act-PST.3SG on DEF oar VPR REL MSE toe leid-de dat de bal op en neer to lead-PST.3SG REL DEF ball up and down bots-te. $^{15}$ bounce-PST.3SG

f. $\quad\left[\mathbf{d o}^{\prime}(\right.$ Felix, Ø)] CAUSE [[do' (roeispaan, Ø)] CAUSE [do' (bal, [bounce' (bal)])]]

Causative accomplishments and causative achievements clearly allow instruments. In fact, due to the clarity of such examples, many examples in this dissertation are causative accomplishments or achievements. Further consider (42a) and (42d); they pass the paraphrase and so correlate with the LSs in (42c) and (42f), respectively. However, causative accomplishments can also feature implements $(42 \mathrm{~g}-42 \mathrm{i})$.

(42) a. Max melted the ice with the hair dryer.

Causative accomplishment

b. Max acted on the hair dryer causing it to melt the ice.

c. $\quad\left[\right.$ do' $\left.^{\prime}(\operatorname{Max}, \varnothing)\right]$ CAUSE [[do' (hair dryer, Ø)] CAUSE [BECOME melted' (ice)]]

d. Max smolt het ijs met de haardroger. Max melt \PST.3SG DEF ice with DEF hairdryer (Dutch)

15 The phrase op en neer ('up and down') was included in the Dutch paraphrase, because without the causative auxiliary doen, botsen translates as collide. 
e. Max werk-te op de haardroger in, Max act-PST.3SG on DEF Hair dryer VPR wat er-toe leid-de dat die het REL MSE-to lead-PST.3SG REL DEM DEF ijs smolt. ice melt $\backslash$ PST.3SG

f. [do' (Max, Ø)] CAUSE [[do' (haardroger, Ø)] CAUSE [BECOME melted' (ijs)]]

g. The boy put together the bike with a manual. (Farrell 2009: 189-190)

h. $\quad$ "The boy acted on the manual, causing it to put together the bike.

i. $\quad\left[\right.$ do' $^{\prime}($ boy, $\left.\varnothing)\right]$ CAUSE [BECOME together' (bike) $\wedge$ use' (boy, manual)] (Farrell 2009: 189-190). ${ }^{16}$

Causative achievements show a similar pattern:

(43) a. Lauren popped the balloon with the pen. Causative achievement

b. Lauren acted on the pen, causing it to pop the balloon.

c. [do' (Lauren, Ø)] CAUSE [[do' (pen, Ø)] CAUSE [INGR popped' (balloon)]]

d. Lauren deed de ballon spring-en met Lauren do\PST.3SG DEF balloon burst-INF with een Balpen.

INDEF pen (Dutch)

e. Lauren werk-te op de pen in, Lauren act-PST.3SG on DEF pen VPR wat er-toe leid-de dat die de ballon REL MSE-to lead-PST.3SG REL DEM DEF balloon deed spring-en. cause.AUX\PST burst-INF

16 This LS is given by Farrell. While I agree that (42g) features an implement, I do not agree with the LS he proposes. I return to this issue in chapter 7. 
f. [do' (Lauren, Ø)] CAUSE [[do' (balpen, Ø)] CAUSE [INGR popped' (ballon)]]

Likewise, causative semelfactives allow for instruments:

(44) a. Sam flashed the light with a stick.

Causative semelfactive

b. Sam acted on the stick, causing the light to flash.

c. [do' $($ Sam, Ø)] CAUSE [[do' (stick, Ø)] CAUSE [SEML do' (light, [flash' (light)])]]

d. Sam deed de lamp flits-en met een Sam do\PST.3SG DEF lamp flash-INF with INDEF stok.

stick (Dutch)

e. Sam werk-te op de stok in, Sam act-PST.3SG on DEF stick VPR wat er-toe leid-de dat die de lamp REL MSE-to lead-PST.3SG REL DEM DEF lamp deed flits-en. cause.AUX\PST flash-INF

f. $\quad\left[\right.$ do' $^{\prime}($ Sam, $\left.\varnothing)\right]$ CAUSE $\left[\left[\right.\right.$ do' $^{\prime}($ stok, $\left.\varnothing)\right]$ CAUSE [SEML do' (lamp, [flash' (lamp)])]]

The only way to express (44a) in Dutch is to use a causative auxiliary doen $((44 \mathrm{~d}))$.

Causative active accomplishments that feature an instrument are a bit more complex. Consider an example with its logical structure:

(45) a. Mary fed the pizza to the child.

b. [do' (Mary, Ø)] CAUSE [do' (child, [eat' (child, pizza)]) \& INGR consumed' (pizza)]

c. Mary fed the pizza to the child with a fork.

What LS would fit (45c)? The paraphrase in (46a) is clearly not acceptable, ruling out the LS in (46b). 
(46) a. *Mary acted on the fork, causing to it to force the child to eat.

b. * $\quad[$ do' (Mary, Ø)] CAUSE [[do' (fork, Ø)] CAUSE [do' (child, [eat' (child, pizza)]) \& INGR consumed' (pizza)]]

c. $\quad\left[\right.$ do' $^{\prime}$ (maejto, Ø)] CAUSE $\left[\left[\right.\right.$ do' $^{\prime}$ (usi, Ø)] CAUSE [BECOME have' (yoem, mansana)]]

d. $U$ maejto- $\varnothing$ usi-ta mansana-ta

DET teacher-NOM child-ACC apple-ACC

yoem-ta miik-tua- $k$.

man-ACC give-CAUS-PERF (Yaqui, Uto-Aztecan)

'The teacher made the child give the man the apple.'

(Guerrero \& Van Valin 2004: 312)

However, the Yaqui sentence in (46d) is acceptable with its corresponding LS in (46c). However, in (46d), event 1 is the teacher causing the child to give the apple, and event 2 is the child giving the man the apple. The sentence in (45a), however, describes an event 1 where Mary causes the child to eat and event 2 is the eating and finishing event. Adding an instrument $((45 \mathrm{c}))$, modifies both events taken together, not just one of them. By contrast, child in (46d) does not modify the whole event. Therefore, an appropriate paraphrase of (45c) is given in (47) below.

(47) Mary caused the child to eat and finish the pizza and used a fork to accomplish this.

To capture the scope that the instrument has, I propose the LS in (48).

[[do' (Mary, Ø)] CAUSE [do' (child, [eat' (child, pizza)]) \& INGR consumed' $($ pizza) $] \wedge\left[\right.$ do' $^{\prime}\left(\right.$ Mary, $\left[\right.$ use' $^{\prime}$ (Mary, fork)])]]

It is necessary to repeat the $\mathbf{d o}^{\prime}$ predicate at the end to ensure the right scope relations. As the fork is the y-argument of a use'-predicate, it is an implement in this example. It cannot be an instrument, because it is not an effector-argument (x-argument of do') anywhere.

Caused motion verbs do allow for instruments as (49) illustrates. 
(49) a. Sonia moved the hay bale to the hangar with a crane.

b. Sonia acted on the crane causing it to move the hay bale to the hangar.

c. $\quad\left[\right.$ do' $^{\prime}($ Sonia, $\left.\varnothing)\right]$ CAUSE $\left[\left[\right.\right.$ do' $^{\prime}($ crane, $\left.\varnothing)\right]$ CAUSE $\left[\right.$ do' $^{\prime}$ (hay bale, [move' (hay bale)]) \& INGR be-at' (hangar, hay bale)]]

It seems that causative active accomplishments allow for instruments, similar to the other causative classes. However, if the tool has scope over the entire event, only an implement is possible. It is quite likely that the microsemantics of the predicate will be influential in determining whether an instrument or an implement is realized.

This section provided an overview of verb classes and their ability to occur with instruments or implements. It was shown that, confirming the prediction, implements require the presence of a $\mathbf{d o}^{\prime}$ in the logical structure. Instruments, on the other hand, require at least one causal operator in the LS. It was shown that causative active accomplishments were capable of having both. Causees taking instruments complicate matters considerably and this matter will be explored in chapter 7. A summary of verb classes and instruments/implements is given in table 17. 


\begin{tabular}{|l|l|}
\hline Verb class & Takes \\
\hline State & None \\
\hline Activity & Implement \\
\hline Achievement & None \\
\hline Semelfactive & Implements (peripherally) \\
\hline Accomplishment & None \\
\hline Active Accomplishment & Implement \\
\hline Casuative state & Instrument \\
\hline Causative activity & Instrument \\
\hline Causative achievement & Instrument \\
\hline Causative accomplishment & Instrument and implement \\
\hline Causative semelfactive & Instrument \\
\hline Causative Active Accomplishment & Instrument and implement \\
\hline
\end{tabular}

Table 17: Verb classes and the prevalence of instruments and implements.

The mechanics behind the expansion of the base logical structures with implements, instruments and the subsequent linking to syntax will be the topic of chapter 8.

\subsection{Integrating the actionality scale with logical structures}

Generally speaking, RRG recognizes that selectional restrictions can be placed on argument positions (Van Valin 2013: 88). RRG has adopted Pustejovsky's Qualia theory as an important mechanism to account for selectional restrictions. It allows one to annotate argument positions in terms of qualia features: Annotated positions can only be filled by referents that meet the requirements expressed by the annotation. For instance, if the referent has to be spherical in nature, there will be an annotation on the argument position with that information in the formal role. This constitutes a type of hard constraint. In order to make softconstraint selectional restrictions in RRG more explicit and put them in 
line with my approach on instruments, I propose to connect the actionality scale with the argument positions in the LS, similar to qualiaannotations.

I assume that a number of referents with similar features are acceptable to fill a given argument position. Rather than decomposing the actionality scale into several features belonging to the qualia roles and specifying ranges for each of them, I propose to directly plug in the actionality scale into the LS. Qualia and the actionality scale are complementary: Qualia annotations can provide very precise information about a referent. For instance, it can specify that a referent filling a given argument position must be able to create lines on a surface (i.e. write). By contrast, the actionality scale can provide a very general range from which referents can be drawn, without zeroing in on very precise attributes. Even though this might seem straightforward on a conceptual level, it is important to provide a technical account for it.

I have proposed the actionality scale explicitly as a Cartesian axissystem. It is therefore possible to define coordinates in the system. However, in most cases we cannot simply annotate an argument position with a simple set of coordinates because that would constitute a hard constraint. We would in effect be coercing the argument position to be filled with a very specific referent (or type of referent). This is a possibility for dealing with verbs with rather specific requirements such as those that lexicalize agency. Because most verbs are flexible with respect to their slot fillers, we have to devise something more complex. The coordinate approach provides us with a powerful system to do so, however. As I have defined the axes explicitly, it is possible to express referent requirements in a variety of ways: This approach allows us to specify whole regions of semantic space or minimum requirements on one or both axes. Consider the requirements ${ }^{17}$ in (50) with their formulations. Recall that the $\mathrm{x}$-axis is the animacy hierarchy and the $\mathrm{y}$-axis is the autonomy hierarchy.

17 These coordinates are randomly chosen. They are for illustration purposes only. 
(50)
a. $(5,2)$
b. $(5, \varnothing)$
c. $(\varnothing, 5)$
d. $\quad(5,2) \leftrightarrow(5,6)$
e. $\quad(5 \uparrow, 2 \uparrow)$
f. $\quad(5 \downarrow, 2 \downarrow)$
g. $\quad(5 \downarrow, 2 \uparrow)$
h. $(\varnothing, \varnothing)$

Filler must be at these exact coordinates. Filler must have a value of 5 on the $\mathrm{x}$ axis. Y-axis is unspecified.

Filler must have a value of 5 on the $y-$ axis. $\mathrm{X}$-axis is unspecified.

Filler must have a value between the coordinates indicated.

Filler must have an $\mathrm{x}$-value of 5 or higher and a y-value of 2 or higher. Filler must have an $\mathrm{x}$-value of 5 or lower and a y-value of 2 or lower. Filler must have an $\mathrm{x}$-value of 5 or lower and a $y$-value of 2 or higher. Both the $\mathrm{x}$ - and the $\mathrm{y}$-axis are unspecified.

This system allows for an immense range of possible combinations, only a subset of which is displayed here. It is very important, however, to point out that the actionality scale and its coordinate-based component are still parts of human cognition. They are modeled loosely on mathematical concepts yet do not describe a mathematical universe. Determining whether a referent has an x-value of exactly 5 or is in fact a bit higher or lower is difficult and will in all likelihood be different for different speakers. Consider then, what an annotated logical structure could look like: ${ }^{18}$

$$
\begin{aligned}
& \text { [do' }(\mathrm{x}, \varnothing)] \text { CAUSE [[do' }(\mathrm{y}, \varnothing)] \text { CAUSE [INGR pred' }(\mathrm{z})]] \\
& (5 \uparrow, 2 \uparrow) \quad(4,1) \leftrightarrow(5,3) \quad(\varnothing, \varnothing)
\end{aligned}
$$

I have opted for a second line of information instead of the usual qualiaannotation as subscripts for the simple reason of legibility.

18 Here too, the numbers are intended for illustration purposes only. 


\subsection{The three problems revisited}

Three problems with respect to ISA were introduced in chapter 3 . The first problem relates to variation with respect to instruments: With the same predicate, some instruments allow for ISA whereas others do not. Consider:

(52) a. John destroyed the sign with the bomb.

b. The bomb destroyed the sign.

c. John destroyed the sign with the sword.

d. $\quad$ *The sword destroyed the sign.

The actionality scale can account for this: The acceptability of ISA depends on the position of the instrument's referent on the scale. The referents have to be high enough on the actionality scale relative to the predicate for ISA to take place. Sword is simply not high enough, but bomb is. Both referents rank as concrete entities on the animacy hierarchy, but sword ranks lower than bomb on the autonomy hierarchy: The former is non-autonomous whereas the latter is semi-autonomous. The semantics of the predicate exclude sword because it is not located in the correct portion of semantic space. However, it would be too quick to conclude that languages will set a general lower limit for ISA in terms of the actionality scale. The problem is that - within the same language the same referent can undergo ISA with some predicates but not with others, even if both are causally embedded. This can be illustrated by keeping the instrument the same, but varying the predicate: For example, ISA is not possible in (53a-53b), (53e-53f) and (53k-53l) whereas it is possible in $(53 c-53 d),(53 g-53 h)$ and $(53 i-53 j)$.

(53) a. Fohn opened the parcel with the knife.

b. $\quad{ }^{*}$ The knife opened the parcel.

c. Greg shattered the window with the knife.

d. The knife shattered the window.

e. The assassin murdered the mayor with a spear through the heart.

f. $\quad$ "The spear murdered the mayor. 
g. The assassin killed the mayor with a spear through the heart.

h. The spear killed the mayor.

i. $\quad$ The cook cracked open the coconut with the hammer.

j. $\quad$ The hammer cracked open the coconut.

$\mathrm{k}$. The cook opened the door with the hammer.

1. ${ }^{*}$ The hammer opened the door.

The murder example is analyzed as the predicate lexicalizing agency (Van Valin \& Wilkins 1996) which is why it is incompatible with a nonhuman actor. Traditionally, RRG includes a special operator ('big' DO) in the logical structure that is said to express lexicalized agency as is the case in (53e-53f). But predicates without lexicalized agency also play a role, as I have shown in (53a-53d) and (53i-53l). It would be erroneous to claim that open lexicalizes agency the same way that murder does, because open is compatible with non-human actors. Consider (54a-b):
a. Fohn opened the container with a crane.
b. The crane opened the container.
c. John unwillingly opened the parcel with a knife.
d. $\quad$ *The assassin unwillingly murdered the mayor.

Furthermore, open is compatible with agency-canceling adverbs (54c), contrary to the example in (54d). However, I believe it is possible to use the actionality scale as a single account for all these examples: Each individual predicate will impose selectional restrictions on the fillers of its argument positions. Only if the filler of the instrument slot is similar enough to the requirements for the instigator slot can it be assigned actorhood. It is not surprising then that a higher-ranking referent like crane is a better choice for actor than the lower-ranking knife. By contrast, the selectional requirements of shatter are less strict and do allow for lower-ranking referents as actors (such as rock, stick and the like). Ergo, the actionality scale can also provide a solution to the second problem.

The actionality scale can equally provide a solution to the third problem. By way of the very same system of selectional restrictions, language 
differences with respect to ISA can be captured. For example, the English verb cut imposes looser restrictions on the argument position than any of its Dutch equivalents. ${ }^{19}$ Afrikaans, by contrast, patterns like English:

(55) a. Tanisha cut the bread with the knife. (English)

b. The knife cut the bread.

c. Tanisha sneed het brood met het mes.

Tanisha cut $\mid P S T .3 S G$ DEF bread with DEF knife (Dutch)

d. *Het mes sneed het brood. DEF knife cut $\mathrm{PST}$.3SG DEF bread

e. Tanisha sneed het brood met het Tanisha cut $\backslash$ PST.3SG DEF brood with DEF mes door.

mes VPR

f. ???Het mes sneed het brood door. DEF knife cut|PST.3SG DEF bread VPR

g. Johan het die brood met ' $n$ mes John AUX(PST) DEF bread with INDEF knife ges-ny.

PTCP-cut

'John cut the bread with a knife.' (Afrikaans)

h. Die mes het die brood ge-sny

DEF knife AUX.(PST) DEF bread PTCP-cut

The knife cut the bread.'

Similarly, Turkish seems to be less restrictive than Bulgarian (56a-56d) and Estonian seems to be more tolerant than Russian (56e-56h):
a. John
ekme $\breve{g}-i$
bıçak-la kes-ti.
John.NOM bread-ACC.SG knife-INS cut-PST.3SG
'John cut the bread with a knife.' (Turkish)

19 Whereas (55d) is completely ungrammatical, (55f) is slightly less bad. 
b. ?Bıçak ekmeğ-i kes-ti.

knife.NOM bread-ACC.SG cut-PST.3SG.

'The knife cut the bread.'

c. Džon narjaza hljaba s nož.

John cut.PERF.PRS.3SG bread.DEF with knife

'John cut the bread with a knife.' (Bulgarian)

d. ???Nožŭt srjaza hljaba.

knife.DEF cut.PERF.PRS.3SG bread.DEF

'The knife cut the bread.'

e. John lõika-s- $\varnothing$ leiba noa-ga.

John.NOM cut-PST-3SG bread-PART knife-COM

'John cut the bread with the knife.' (Estonian)

f. Nuga lõika-s- $\varnothing$ leib-a.

knife.NOM cut-PST-3SG bread-PART

'The knife cut the bread.'

g. Jon otrezal hleb

John cut.PERF.PST.3SG.M bread.ACC.SG.M

nozhom.

knife.INS.SG.M

'John cut the bread with the knife.' (Russian)

h. "Nozh razrézal hleb.

Knife.NOM.SG cut.PERF.PST.3SG.M bread.ACC.SG.M

'The knife cut the bread.'

Even within the same language family, there can be substantial differences. The alternation between (56a) and (56b) is perfectly possible in Portuguese, somewhat strange but still grammatical in Spanish and utterly ungrammatical in Romanian (Hugo Cardoso, Thomas Brochhagen \& Adina Dragomirescu, p.c.). Higher-ranking referents, such as acid, seem to be unproblematic in most languages:
a. Jon-ek ate- $a$
honda-tu
John-ERG door-DET(SG.ABS) damage-PTCP
du azido-a-rekin.
AUX acid-DET(SG)-COM
'John damaged the door with the acid.' (Basque) 

b. Azido-a-k ate- $a$ honda-tu acid-DET(SG)-ERG door-DET(SG.ABS) damage-PTCP $d u$. AUX

'The acid damaged the door.'

c. John bâ (ân) asid be (ân) dar âsib resând. John with DEM acid to DEM door damage arrive 'John damaged the door with acid.' (Persian)

d. (Ân) asid be (ân) dar âsib resând. DEM acid to DEM door damage arrive 'The acid damaged the door.'

e. '̌on-ma da-a-zian-a k'ar-eb-i John-ERG PR-NV-damage-AOR.S.3SG door-NOM $m \check{z} a v$-it. acid-INS 'John damaged the door with the acid.' (Georgian)

f. Mžava-m da-a-zian-a k'ar-eb-i. acid-ERG PR-NV-damage-PST.AOR.S.3SG door-PL.NOM 'The acid damaged the door.'

g. Jón skemm-d-i dyr-nar með Jón.NOM.SG damage-PST-3SG door-DEF.ACC.PL with sýr-u. acid-DAT

'John damaged the door with the acid.'(Icelandic) ${ }^{20}$

h. Sýran kemm-d-i dyr-nar.

Acid-DEF.NOM.SG damage-PST-3SG door-DEF.ACC.PL 'The acid damaged the door.'

Even though individual languages vary, some generalizations across languages present themselves. For instance, not a single Slavic language in the sample allowed for the example in (56b). Generally, Slavic seems to be fairly restricted with respect to ISA, whereas English and Portuguese are the most liberal languages in the sample.

20 Dyr is plural in Icelandic (Felix Knuth, p.c.). 
All three problems can be accounted for with the same approach based on the actionality scale. As I have shown, I propose to follow Grimm in assuming that argument positions are open to different sections of semantic space. In RRG-terms, this translates to argument positions in the logical structure being open to different sections of the scale. For example, the verb kill will have higher requirements than cut and murder will have even higher requirements than kill. Higher requirements translate to smaller portions of semantic space that referents can be drawn from. In other words, the three problems can be accounted for by the same system: Accessible regions of semantic space, dependent on the predicate and the language. By plugging the actionality scale into qualia theory, it can be integrated in a practical system of linking from semantics to syntax.

\subsection{A different approach to the semantic range}

In this chapter, I proposed an overhaul of the concept of animacy. More specifically, I proposed including a second axis, which I dubbed autono$m y$, so as to arrive at a Cartesian axis system that allows us to classify the referents of arguments more precisely. Furthermore, the use of such a system allows us to define regions of semantic space along principled lines which are directly compatible with RRG's linking system. However, in the CRC 991, Barsalou's (1992) frames are recognized as a universal format of human cognition (Löbner 2014: 23-24, 2015: 15) and are being developed to be applicable across different scientific fields (e.g. Petersen 2007/2015, Kallmeyer \& Osswald 2013). As such, it is possible to provide a frame analysis of the concepts explored in this chapter. In this section, I will propose a very preliminary modeling of the actionality scale in terms of a multiple inheritance hierarchy (Osswald 2002: 12ff.). Osswald (p.c.) points out that my actionality scale-approach is useful for capturing some of the properties of referents, especially those concerning instruments, causees and the like. However, it is difficult to translate the actionality scale into the CRC's frame approach without an intermediate 
step, as the architecture of the actionality scale does not allow for a direct translation. That is to say, it first has to be translated into another format. This section is intended to explore the intermediate step that is necessary for a translation into frames. According to Osswald (2002: 13), multiple inheritance hierarchies are an example of a multidimensional classification approach. That is, concepts inherit from several superordinate concepts; instead of just one as is the case with the simpler, taxonomic trees. Osswald (2002: 13) points out that with multiple inheritance hierarchies, the concepts are not to be considered subconcepts, but rather as instances of the combination of their superordinates. Such an analysis of the actionality scale is given in figure 38. I have taken concepts of the actionality scale's two axes and used them as concepts in the branches of the tree-structure. For the sake of clarity, figure 38 only shows the feature values (in terms of connecting lines) that are defining characteristics of the concept at hand. For example, human referents are defined as [+sentient] and [+animate]. Needless to say, in prototypical cases, they are also [+movable]. However, non-defining features have not been connected to the concepts to keep the general overview intact. The top section of the animacy hierarchy related to reference $\left(1^{\text {st }}\right.$ person, $2^{\text {nd }}$ person, and $3^{\text {rd }}$ person) has not been included in the tree for the sake of simplicity. Example referents are given in italics. 


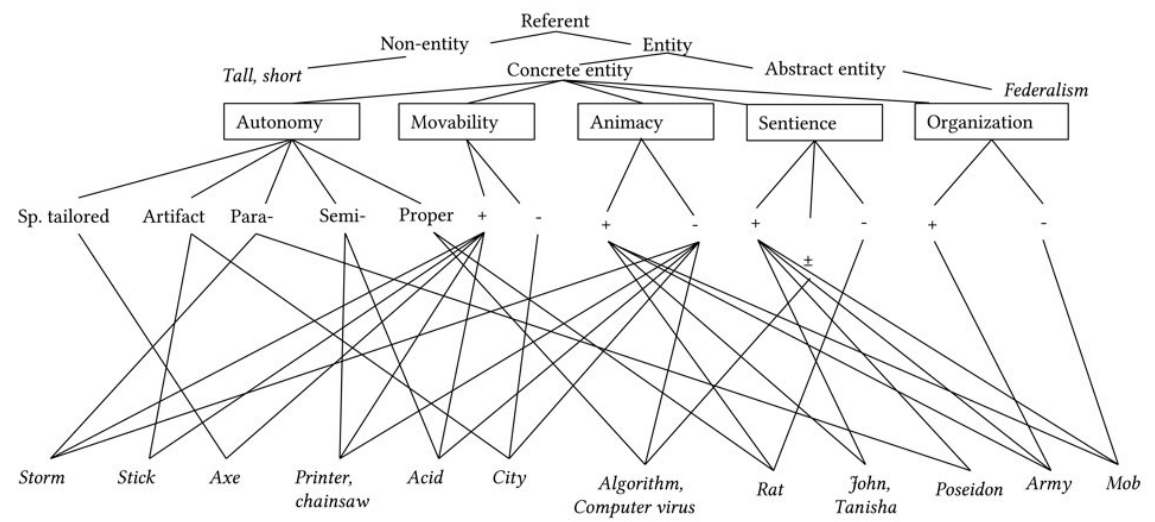

Figure 38: Preliminary Multiple Inheritance Hierarchy analysis of the actionality scale.

Figure 38 reveals that certain features might outrank others. For instance, if a referent is [+sentient], it will automatically be considered autonomous (proper). It is indeed difficult to conceptualize an entity that is [+sentient] and non-autonomous. The graph in figure 38 can be used in future work as a starting point to model the actionality scale with the CRC's frame approach. Doing so here would be beyond the scope of this dissertation. 
